http://dx.doi.org/10.32929/2446-8355.2019v28n3p299-315

\title{
DESEMPENHO PRODUTIVO DO TRIGO EM FUNÇÃO DA DENSIDADE DE SEMEADURA E LÂMINAS DE IRRIGAÇÃO SUPLEMENTAR
}

\author{
Marcos Vinícius Loregian ${ }^{1 *}$, Marcia Xavier Peiter ${ }^{2}$, Adroaldo Dias Robaina², Anderson \\ Crestani Pereira ${ }^{3}$, Luis Humberto Bahú Ben ${ }^{4}$, Jardel Henrique Kirchner ${ }^{5}$, Wellington \\ Mezzomo $^{6}$, Bruna Dalcin Pimenta ${ }^{7}$
}

\footnotetext{
${ }^{1}$ Engenheiro Agrônomo, Mestrando do Programa de Pós-Graduação em Agronomia, Departamento de Fitotecnia, Universidade Federal de Santa Maria (UFSM), Santa Maria - RS, Brasil. *E-mail do autor correspondente: vinicius.loregian@hotmail.com

${ }^{2}$ Engenheiro(a) Agrônomo(a), Professor(a) Dr.(a), Centro de Ciências Rurais, Departamento de Engenharia Rural, Universidade Federal de Santa Maria (UFSM), Santa Maria - RS, Brasil.

${ }^{3}$ Engenheiro Agrônomo, Mestrando do Programa de Pós-Graduação em Engenharia Agrícola, Universidade Federal de Santa Maria (UFSM), Santa Maria - RS, Brasil.

${ }^{4}$ Engenheiro Agrônomo, Doutor em Engenharia Agrícola, Universidade Federal de Santa Maria (UFSM), Santa Maria - RS, Brasil.

${ }^{5}$ Prof ${ }^{\circ}$. Dr. Instituto Federal de Educação, Ciência e Tecnologia do Rio Grande do Sul - Campus Ibirubá/RS, Brasil.

${ }^{6}$ Engenheiro Agrônomo, Doutorando do Programa de Pós-Graduação em Engenharia Agrícola, Universidade Federal de Santa Maria (UFSM), Santa Maria - RS, Brasil.

${ }^{7}$ Prof ${ }^{a}$. MSc. Instituto Federal de Educação, Ciência e Tecnologia do Rio Grande do Sul - Campus Vacaria/RS, Brasil.
}

Recebido: 05/11/2018; Aceito: 29/08/2019

RESUMO: Com o objetivo de avaliar o efeito de diferentes lâminas de irrigação suplementar, densidades de semeadura e a interação destes fatores sobre a produtividade e qualidade de grãos de trigo (Triticum aestivum L.) conduziu-se um experimento em Argissolo Amarelo distrófico típico, no município de Santa Maria - RS, nas seguintes coordenadas geográficas: $29^{\circ} 42^{\prime} 55.30^{\prime \prime} \mathrm{S}$ e 5344'22.56" O. O delineamento experimental foi o de blocos ao acaso com parcelas subdivididas, com quatro repetições, onde as parcelas foram constituídas pelas lâminas de irrigação e as subparcelas pelas diferentes densidades de semeadura. Foram estabelecidas seis lâminas de irrigação: 0, 25, 50, 75, 100 e 125\% da ETo e três densidades de semeadura: 250, 350 e $450 \mathrm{pl} \mathrm{m}^{-2}$. A produtividade mínima de $4165 \mathrm{~kg} \mathrm{ha}^{-1}$ foi observada no tratamento sem irrigação na densidade de $450 \mathrm{pl} \mathrm{m}^{-2}$ e máxima de $6894 \mathrm{~kg} \mathrm{ha}^{-1}$ na lâmina de $100 \%$ da ETo na densidade de $350 \mathrm{pl} \mathrm{m}^{-2}$. A lâmina de irrigação e densidade de semeadura influenciaram significativamente o número de espiguetas por espiga, número de espigas por metro quadrado e massa de mil grãos.

Palavras-chave: Cereais de inverno. Produtividade de grãos. Triticum aestivum L.

\section{PRODUCTIVE PERFORMANCE OF WHEAT IN THE FUNCTION OF SEEDING DENSITY AND SUPPLEMENTARY IRRIGATION}

ABSTRACT: In order to evaluate the effect of different supplementation irrigation slides, sowing density and the interaction of these factors on wheat grain yield and quality (Triticum 
aestivum L.) an experiment was carried out in Typical Yellow Dystrophic Argisol, in the municipality of Santa Maria, RS, at the following geographic coordinates: 29 42'55.30 "S and 534' $22.56^{\prime \prime} \mathrm{W}$. The experimental design was a randomized block design with subdivided plots, with four replications, where the plots were constituted by the irrigation slides and the subplots by the different seeding densities. Six irrigation slides were established: $0,25,50$, 75,100 and $125 \%$ of ETo and three sowing densities: 250,350 and $450 \mathrm{pl} \mathrm{m}^{-2}$. The minimum productivity of $4165 \mathrm{~kg} \mathrm{ha}^{-1}$ and maximum of $6894 \mathrm{~kg} \mathrm{ha}^{-1}$. The irrigation depth and sowing density significantly influenced the number of spikelets per spike, number of spikes per square meter and average weight of a thousand grains.

Key words: Grain yield. Winter cereals. Triticum aestivum L.

\section{INTRODUÇÃO}

Na safra de 2017 o Brasil produziu cerca de 4263,5 mil toneladas de trigo, sendo que deste total $82 \%$ corresponde a produção dos estados do Rio Grande do Sul e Paraná (CONAB, 2018). Embora tenha uma produção relativamente alta do grão, a média de produtividade das lavouras brasileiras ainda é baixa, se comparada ao potencial produtivo desta cultura. De acordo com a Empresa Brasileira de Pesquisa Agropecuária (2018), o rendimento médio de grãos registrados na safra de 2017 foi de $2800 \mathrm{~kg} \mathrm{ha}^{-1}$.

A produção de grãos é uma característica quantitativa complexa, diretamente relacionada com a habilidade da planta translocar e estocar carboidratos nos grãos (SLEEPER; POEHLMAN, 2006). Em cereais como o trigo, esta variável é obtida pelo produto de três componentes principais: número de espigas por unidade de área, número de grãos por espiga e massa média de grãos (SILVA et al., 2015).

De acordo com Avarenga et al. (2009), entre as tecnologias que precisam ser ajustadas para altas produtividades da cultura do trigo, a densidade de semeadura é apontada como um fator de extrema importância, pois influencia diretamente na captação de recursos como radiação, água e nutrientes pelas plantas.

A precipitação pluviométrica é o fator climático que mais limita a obtenção de altas produtividades (SCALCO et al., 2002), de forma que a irrigação torna-se uma prática indispensável para aumentar o rendimento da cultura do trigo, principalmente por garantir a produção da cultura quando ocasionalmente ocorrem períodos de déficit hídrico.

Mudanças na densidade de semeadura exercem efeitos diretos no número de espigas e no rendimento individual de espigas das plantas (OZTURK et al., 2006). Em experimento realizado com diferentes cultivares de trigo, Provenzi et al. (2012) relatam que a alta densidade de plantas pode aumentar o aproveitamento dos recursos do ambiente no início do ciclo de desenvolvimento da cultura, resultando no incremento do número de espigas por área e na produtividade de grãos, embora ressaltem que este aumento na densidade reduz o período fotossinteticamente ativo das folhas baixeiras além de dificultar o controle químico de doenças. 
Por outro lado, em baixas densidades populacionais ocorre um aumento na formação de perfilhos, que pode ser explicado pela alteração na intensidade de competição entre as plantas e isso tende a manter a produção estável (ALMEIDA; MUNDSTOCK, 2001).

Considerando o fator água, embora se trate de uma cultura resistente ao déficit hídrico, alguns estádios de desenvolvimento do trigo são bastante afetados por variações na quantidade de água disponível (ACEVEDO et al., 2002). De acordo com Brunetta et al. (2001), o período de maior demanda hídrica da cultura do trigo vai da elongação ao florescimento, devido ao fato de que é neste período que ocorre o maior acúmulo de massa verde.

Conforme Libardi e Costa (1997), o consumo de água pela cultura do trigo é, em média, de $347,2 \mathrm{~mm}$, o que equivale a uma demanda de $3,02 \mathrm{~mm} \mathrm{dia}^{-1}$ se for considerado um ciclo de 115 dias. No entanto, Azevedo et al. (1994) comentam que para se obter produtividades acima de 6 toneladas são necessárias irrigações maiores que $590 \mathrm{~mm}$.

Atualmente existem vários estudos experimentais que demonstram que os fatores isolados, lâminas de irrigação e densidades de semeadura influenciam a área foliar, matéria seca, produtividade e componentes de produção (ALMEIDA; MUNDSTOK, 2001; AVARENGA et al., 2009; FIOREZE, 2011; OZTURK et al., 2006). No entanto, vale ressaltar que a análise individual desses dois fatores não permite a avaliação da interação entre essas variáveis, para que se possa estabelecer a melhor associação entre níveis de irrigação e densidades de semeadura.

No Rio Grande do Sul, o trigo é a principal alternativa de cultivo de inverno para muitos produtores. Logo, técnicas de manejo que possam trazer melhorias ao sistema produtivo colaboram para o desenvolvimento desta atividade. Com isso, o objetivo deste trabalho foi avaliar as respostas produtivas desta cultura submetida a seis níveis de irrigação suplementar: 0, 25, 50, 75, 100 e $125 \%$ da ETo e três densidades de semeadura: 250, 350 e $450 \mathrm{pl} \mathrm{m}^{-2}$.

\section{MATERIAL E MÉTODOS}

O experimento foi realizado no período de junho a dezembro de 2016, no município de Santa Maria - RS, localizado na Região Central do Estado do Rio Grande do Sul, nas seguintes coordenadas geográficas: 2942'55.30" S e 5344'22.56" O, com altitude de $110 \mathrm{~m}$. O solo da área é classificado como Argissolo Amarelo distrófico típico, de textura franca, caracterizado de acordo com Streck et al. (2008) como o tipo de solo predominante da região.

O clima na região é temperado apresentando característica subtropical com inverno marcante caracterizado pela classificação de Köppen-Geiger, no tipo Cfa (Clima subtropical úmido).

Os resultados da análise química do solo, obtidos antes do início do experimento, estão apresentados na Tabela 1.

A adubação de base foi estabelecida a partir da interpretação da análise química do solo onde se utilizou $250 \mathrm{~kg} \mathrm{ha}^{-1}$ do adubo formulado 05-14-08 $\left(\mathrm{N}-\mathrm{P}_{2} \mathrm{O}_{5}-\mathrm{K}_{2} \mathrm{O}\right)$. A adubação de cobertura, $90 \mathrm{~kg} \mathrm{ha}^{-1}$ de $\mathrm{N}$ (ureia), foi fracionada em duas aplicações ao longo do ciclo da 
cultura, sendo a primeira $\left(45 \mathrm{~kg} \mathrm{ha}^{-1} \mathrm{de} \mathrm{N}\right)$ realizada no início do estádio de perfilhamento e a segunda (45 kg ha-1 de N) no início do estádio de alongamento, correspondentes aos estádios 2 e 6 da escala de Feeks (LARGE, 1954), conforme as recomendações do Manual de Adubação e Calagem para os Estados do Rio Grande do Sul e Santa Catarina.

Tabela 1. Resultados da análise química da área experimental, classificado como Argissolo Amarelo distrófico típico. Results of the chemical analysis of the experimental area, classified as Typical Yellow Dystrophic Argisol.

\begin{tabular}{|c|c|c|c|c|c|c|c|c|c|c|c|c|}
\hline \multirow{2}{*}{$\begin{array}{l}\text { Prof. } \\
(\mathrm{m})\end{array}$} & \multirow{2}{*}{$\begin{array}{c}\mathrm{pH} \\
\text { água }\end{array}$} & \multirow[t]{2}{*}{$\mathrm{Ca}$} & \multirow[t]{2}{*}{$\mathrm{Mg}$} & \multirow{2}{*}{\multicolumn{2}{|c|}{$(\mathrm{H}+\mathrm{Al})$}} & \multirow{2}{*}{$\begin{array}{l}\text { CTC } \\
\text { Efet. }\end{array}$} & \multicolumn{2}{|c|}{$\begin{array}{c}\text { Saturação } \\
(\%)\end{array}$} & \multirow{2}{*}{$\begin{array}{l}\text { Índice } \\
\text { SMP }\end{array}$} & \multirow[t]{2}{*}{$\begin{array}{l}\mathrm{MO} \\
(\%)\end{array}$} & \multirow[t]{2}{*}{ S } & \multirow{2}{*}{$\begin{array}{c}\text { P- } \\
\text { Mehlich } \\
\mathrm{dm}^{-3}\end{array}$} \\
\hline & & & & & & & $\mathrm{Al}$ & Base & & & & \\
\hline $0-0,1$ & 5,8 & 9,7 & 3,5 & 0,2 & 3,9 & 13,8 & 1,6 & 76,1 & 6,2 & 3,3 & 11,0 & 14,2 \\
\hline $0,1-0,3$ & 5,2 & 8,5 & 2,4 & 0,8 & 6,6 & 12,0 & 7,9 & 63,4 & 5,8 & 2,5 & 7,1 & 11,5 \\
\hline
\end{tabular}

Para determinação das características físicas foram coletadas amostras nas profundidades de 0 a 1,0 m, estratificadas a 0,2 m. A capacidade de campo foi determinada pelo método direto, a densidade aparente do solo foi realizada por meio do método do cilindro (EMBRAPA, 2011). Os dados obtidos a partir da análise são demonstrados na Tabela 2.

Tabela 2. Características físico-hídricas da área experimental. Physical-water characteristics of the experimental area.

\begin{tabular}{ccccc}
\hline $\begin{array}{c}\text { Profundidade } \\
(\mathrm{m})\end{array}$ & $\begin{array}{c}\text { Densidade } \\
\text { aparente } \\
\left(\mathrm{t} \mathrm{m}^{-3}\right)\end{array}$ & $\begin{array}{c}\text { Capacidade de } \\
\text { campo } \\
\left(\mathrm{m}^{-3} \mathrm{~m}^{-3}\right)\end{array}$ & $\begin{array}{c}\text { Ponto de } \\
\text { Murcha } \\
\left(\mathrm{m}^{-3} \mathrm{~m}^{-3}\right)\end{array}$ & Textura \\
\hline $0-0,2$ & 1,42 & 0,31 & 0,14 & Franco \\
$0,2-0,4$ & 1,38 & 0,34 & 0,17 & Franco argiloso \\
$0,4-0,6$ & 1,36 & 0,37 & 0,23 & Argila \\
$0,6-0,8$ & 1,30 & 0,36 & 0,24 & Argila \\
$0,8-1,0$ & 1,30 & 0,35 & 0,23 & Franco siltoso \\
\hline
\end{tabular}

Foi utilizada a cultivar de trigo BRS Marcante, que possui ciclo médio e alta capacidade de perfilhamento além de estar alinhada com os princípios de produtividade de grãos, bom perfil para panificação e boa resistência a doenças foliares (EMBRAPA, 2018). A cultura foi implantada no sistema de semeadura direta, com o auxílio de uma semeadora com espaçamento de $0,17 \mathrm{~m}$ entrelinhas em uma profundidade de $3 \mathrm{~cm}$.

O delineamento experimental utilizado foi o de blocos ao acaso (DBA) com parcelas subdivididas, com quatro repetições, onde as parcelas foram constituídas por seis lâminas de irrigação suplementar $(0 \%, 25 \%, 50 \%, 75 \%, 100 \%$ e $125 \%$ da evapotranspiração de referência) e as subparcelas pelas diferentes densidades de semeadura (D1: $250 \mathrm{pl} \mathrm{m}^{-2}$; D2: $350 \mathrm{pl} \mathrm{m}^{-2}$; D3: $450 \mathrm{pl} \mathrm{m}^{-2}$ ).

O manejo da irrigação foi realizado com base na evapotranspiração de referência (ETo), determinada pela equação de Penman-Monteith/FAO (ALLEN et al., 1998). Os dados climáticos foram obtidos na estação automática da Universidade Federal de Santa Maria, vinculada ao Instituto Nacional de Meteorologia, localizada a $2.000 \mathrm{~m}$ da área experimental, sendo monitoradas as seguintes variáveis: precipitação pluvial $(\mathrm{mm})$; temperatura máxima e 
mínima $\left({ }^{\circ} \mathrm{C}\right)$; umidade relativa do ar máxima e mínima $(\%)$; insolação (h) e velocidade do vento $\left(\mathrm{m} \mathrm{s}^{-1}\right)$.

Levando em consideração que o aporte de água para a cultura é proveniente da precipitação e da irrigação, foi necessário descontar do volume total de água a ser aplicado na irrigação o valor referente à precipitação pluvial efetiva ocorrida entre duas irrigações consecutivas (considerando $70 \%$ da precipitação), de acordo com a metodologia proposta por Millar (1978).

As irrigações foram realizadas em turno fixo de sete dias, sempre que a ETo fosse superior à precipitação pluvial efetiva naquele período. Para isso, utilizou-se um sistema de irrigação por aspersão convencional composto por uma linha principal e doze linhas laterais fixas medindo $24 \mathrm{~m}$ cada uma, sendo todas de PVC. O espaçamento utilizado entre as linhas laterais e aspersores foi de 4 x $4 \mathrm{~m}$. Para determinação das lâminas de irrigação foi adotada a experimentação do Coeficiente de Uniformidade de Christiansen (CUC) verificado após a instalação do sistema de irrigação e ajustado através do tempo de funcionamento do sistema.

O número de irrigações, as lâminas aplicadas e a precipitação ocorridas durante a condução do experimento estão representadas na Tabela 3.

Tabela 3. Número de irrigações, irrigação total $(\mathrm{mm})$, evapotranspiração de referência $(\mathrm{mm})$, precipitação pluvial efetiva $(\mathrm{mm})$ e total de água aplicada $(\mathrm{mm})$ na cultura do trigo submetido a lâminas de irrigação e densidades de plantas. Number of irrigations $(\mathrm{mm})$, total irrigation $(\mathrm{mm})$, reference evapotranspiration $(\mathrm{mm})$, effective rainfall $(\mathrm{mm})$ and total water applied ( $\mathrm{mm})$ on wheat in the function of seeding density and supplementary irrigation.

\begin{tabular}{cccccc}
\hline Tratamento & $\begin{array}{c}\mathrm{N}^{\text {o de }} \\
\text { Irrigações }\end{array}$ & $\begin{array}{c}\text { Irrigação } \\
\text { Total } \\
(\mathrm{mm})\end{array}$ & $\begin{array}{c}\text { Evapotranspiração } \\
\text { de Referência } \\
(\mathrm{mm})\end{array}$ & $\begin{array}{c}\text { Prec. Pluvial } \\
\text { efetiva (mm) }\end{array}$ & $\begin{array}{c}\text { Total de } \\
\text { água (mm) }\end{array}$ \\
\hline 1- Testemunha & 0 & 0,0 & 250,1 & 413,0 & 413,0 \\
$2-25 \%$ ETo & 6 & 20,0 & 250,1 & 413,0 & 433,0 \\
$3-50 \%$ ETo & 6 & 40,0 & 250,1 & 413,0 & 453,0 \\
$4-75 \%$ ETo & 6 & 60,0 & 250,1 & 413,0 & 473,0 \\
$5-100 \%$ ETo & 6 & 80,1 & 250,1 & 413,0 & 493,1 \\
$6-125 \%$ ETo & 6 & 100,1 & 250,1 & 413,0 & 513,1 \\
\hline
\end{tabular}

Na Figura 1 está representado o momento das irrigações, a evapotranspiração de referência e o volume de precipitação efetiva acumulada em intervalos semanais. Durante o ciclo de cultivo do trigo foram realizadas seis irrigações, onde a precipitação efetiva ocorrida no período experimental totalizou um volume de $413 \mathrm{~mm}$.

Salienta-se que esta precipitação seria insuficiente para suprir adequadamente as necessidades hídricas da cultura do trigo para um rendimento acima de 6 toneladas por hectare, como menciona Azevedo et al. (1994). Estes autores afirmam que são necessárias irrigações acima de $590 \mathrm{~mm}$ para se obter tais produtividades. A necessidade de complementação hídrica pela irrigação foi necessária devido à distribuição irregular da chuva, com veranicos durante o experimento. 


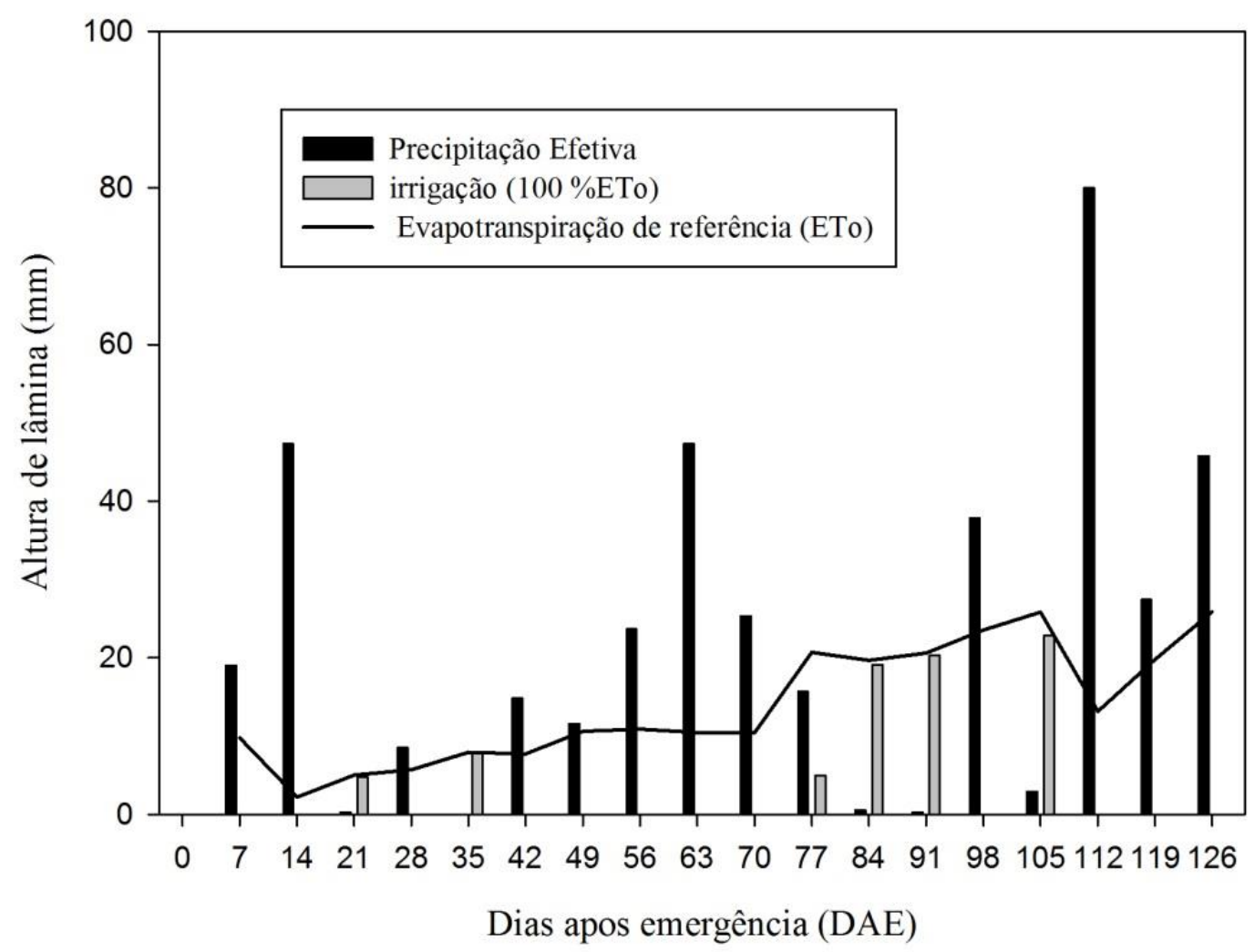

Figura 1. Precipitação efetiva, evapotranspiração de referência e irrigações realizadas na lâmina de reposição de água de $100 \%$ da evapotranspiração de referência acumulada em sete dias. Effective precipitation, reference evapotranspiration and irrigations performed on the $100 \%$ water replacement blade of the reference evapotranspiration accumulated in seven days.

As respostas aos tratamentos foram avaliadas por meio dos seguintes componentes de produtividade: número de espigas por unidade de área, número de espiguetas por espiga, número de grãos por espiga, massa de mil grãos, peso do hectolitro e rendimento de grãos.

A colheita do trigo foi realizada de forma manual e individualmente em cada unidade experimental aos 136 dias após a emergência plena das plantas, momento em que cerca de 90\% das espigas apresentavam grãos com coloração típica de maduro e teor de água médio de $12 \%$.

O número de espigas por metro quadrado foi estimado pelo total de espigas em dois metros lineares de cada unidade experimental. Após a colheita foi realizada uma amostragem de grãos, da qual foram retiradas amostras de mil sementes que foram pesadas e tiveram a umidade corrigida (13\% b.s.) para obtenção da massa média de mil grãos. A amostra para determinação deste parâmetro foi retirada do total de grãos provenientes de cada unidade experimental.

Para determinação do número de grãos por espiga e número médio de espiguetas foram colhidas dez espigas de trigo, ao acaso, na área útil de cada subparcela. 
A análise estatística para interpretação dos resultados foi realizada utilizando-se o software SISVAR for Windows, versão 9.1, desenvolvido pela Universidade Federal de Lavras (UFLA). As médias do número de grãos por espiga, do número de grãos por espigueta, do número de grãos por metro quadrado e da massa de mil grãos, que tiveram efeito significativo, foram analisadas por regressão para o efeito de densidade de semeadura.

\section{RESULTADOS E DISCUSSÃO}

A análise de variância apresentou efeito significativo da lâmina de irrigação e densidade de semeadura sobre o número de espiguetas por espiga, número de espigas por metro quadrado e massa de mil grãos (Tabela 4). O comprimento de espiga e número de grãos por espiga foram influenciados significativamente apenas pela densidade de semeadura, enquanto, o peso do hectolitro e a produtividade final da cultura foram significativos apenas para lâmina de irrigação. A interação entre os fatores exerceu influência significativa sobre a massa de mil grãos e peso do hectolitro. Os rendimentos de grãos e os componentes de rendimento foram influenciados pela variação na densidade de plantas.

Tabela 4. Resumo da análise de variância para comprimento de espiga (CE), número de espiguetas por espiga (NEE), número de grãos por espiga (NGE), número de espigas por $\mathrm{m}^{-2}$ (NE), massa de mil grãos (MMG), peso do hectolitro $(\mathrm{pH})$ e produtividade de trigo (PROD) sob seis lâminas de irrigação (L) e três densidades de semeadura (D). Summary of variance analysis for ear length (CE), number of spikelets per spike (NEE), number of grains per spike $(N G E)$, number of ears per $m^{-2}(N E)$, mass of a thousand grains (MMG), hectoliter weight $(p H)$ and wheat yield (PROD) under six irrigation slides $(L)$ and three sowing densities $(D)$.

\begin{tabular}{c|c|c|c|c|c|c|c}
\hline $\begin{array}{c}\text { Fonte de } \\
\text { variação }\end{array}$ & CE & NEE & NGE & NE & MMG & pH & PROD \\
\hline Bloco & $2,399 \mathrm{~ns}$ & $5,186^{*}$ & $8,518^{*}$ & $15,510^{*}$ & $1,441 \mathrm{~ns}$ & $2,958^{*}$ & $8,867^{*}$ \\
L & $2,300 \mathrm{~ns}$ & $2,718^{*}$ & $0,577 \mathrm{~ns}$ & $6,300^{*}$ & $22,291^{*}$ & $3,256^{*}$ & $7,826^{*}$ \\
$\mathrm{D}$ & $5,453^{*}$ & $20,094^{*}$ & $6,601^{*}$ & $3,874^{*}$ & $22,855^{*}$ & $1,641 \mathrm{~ns}$ & $2,841 \mathrm{~ns}$ \\
L X D & $0,225 \mathrm{~ns}$ & $0,409 \mathrm{~ns}$ & $0,053 \mathrm{~ns}$ & $1,160 \mathrm{~ns}$ & $2,713^{*}$ & $2,492^{*}$ & $0,472 \mathrm{~ns}$ \\
\hline
\end{tabular}

ns: não significativo; *significativo a 0,05 de probabilidade pelo teste F. ns: not significant; *significant at 0.05 probability by $F$ test.

A variação no comprimento de espigas (CE) apresentou efeito significativo para o fator densidade. Na Figura 2 é possível observar que os maiores valores para este componente ocorreram na menor densidade de semeadura $\left(250 \mathrm{pl} \mathrm{m}^{-2}\right)$. O comprimento médio de espigas apresentou variação entre 8,9 e $9,5 \mathrm{~cm}$ para a densidade de $250 \mathrm{pl} \mathrm{m}^{-2}, 8,7$ e 9,5 para a densidade de $350 \mathrm{pl} \mathrm{m}^{-2}$ e 8,2 e 9,15 na densidade de $450 \mathrm{pl} \mathrm{m}^{-2}$. 


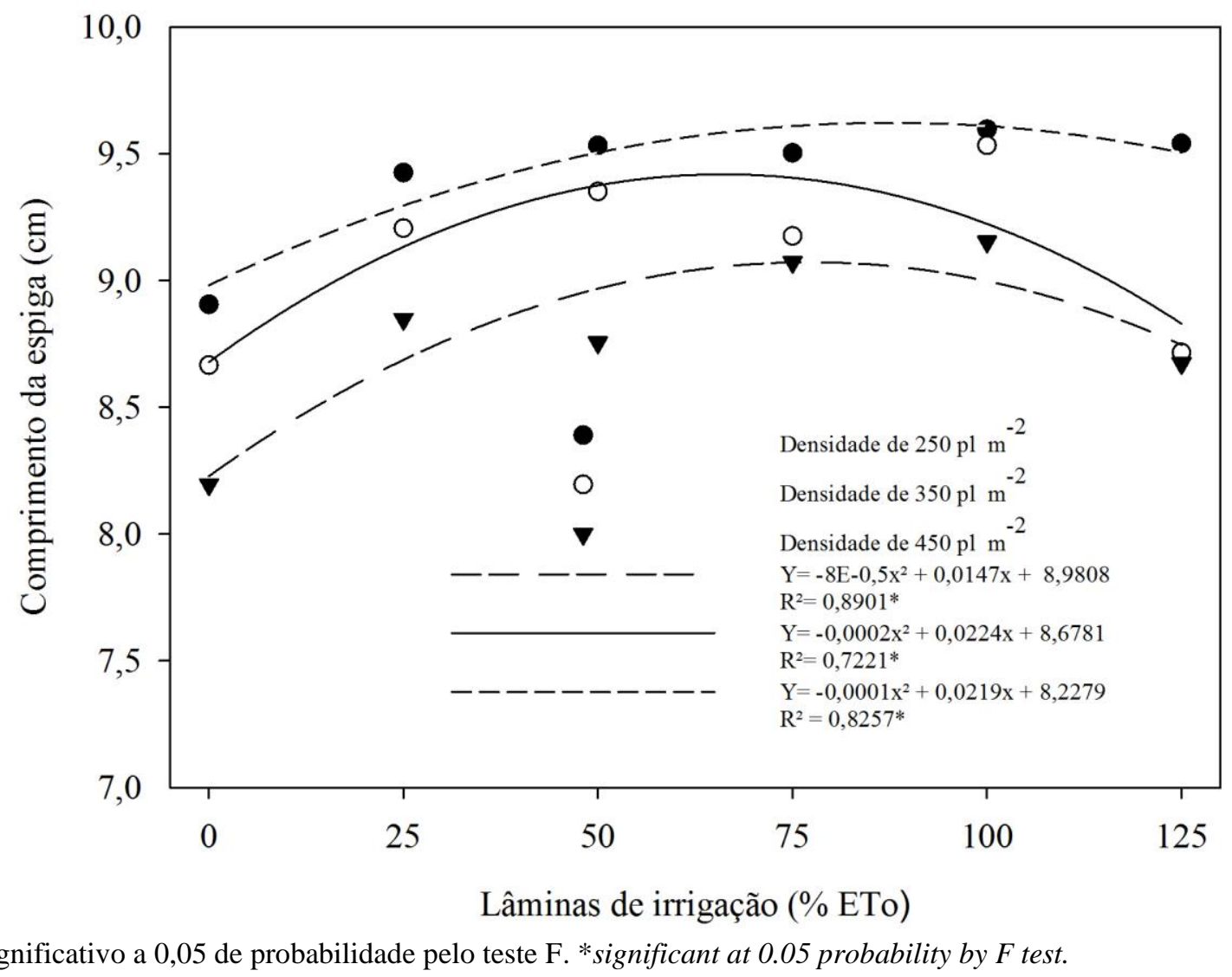

Figura 2. Variação no comprimento de espigas de trigo em função de diferentes densidades de semeadura e lâminas de irrigação suplementar. Variation in the length of wheat ears due to different seeding densities and supplementary irrigation slides.

Isto pode ser explicado, em parte, pela redução da competição intraespecífica que ocorre na população de plantas de $250 \mathrm{pl} \mathrm{m}^{-2}$ em relação às cultivadas em maiores densidades. Nestas, a planta é capaz de captar mais recursos do meio e utilizá-los para melhorar seus atributos morfológicos, produzindo, por exemplo, espigas maiores (GROSS et al., 2012).

Os pontos de máxima eficiência técnica para a variável comprimento de espiga foram obtidos nas lâminas de 76,3\% da ETo $(8,89 \mathrm{~cm}), 56,0 \%$ da ETo $(9,31 \mathrm{~cm})$ e 109,5\% $(9,63 \mathrm{~cm})$ para as densidades de 250,350 e $450 \mathrm{pl} \mathrm{m}^{-2}$, respectivamente.

Em relação à variação do número de espiguetas por espiga, esta apresentou diferença significativa em função das diferentes lâminas de irrigação e densidades de semeadura. De acordo com a Figura 3, observa-se que, assim como ocorreu para o comprimento da espiga, os maiores valores foram observados na menor densidade de semeadura $\left(250 \mathrm{pl} \mathrm{m}^{-2}\right)$, onde o maior valor $(18,9 \mathrm{~cm})$ foi obtido no tratamento que corresponde a lâmina de irrigação de $100 \%$ da ETo. 


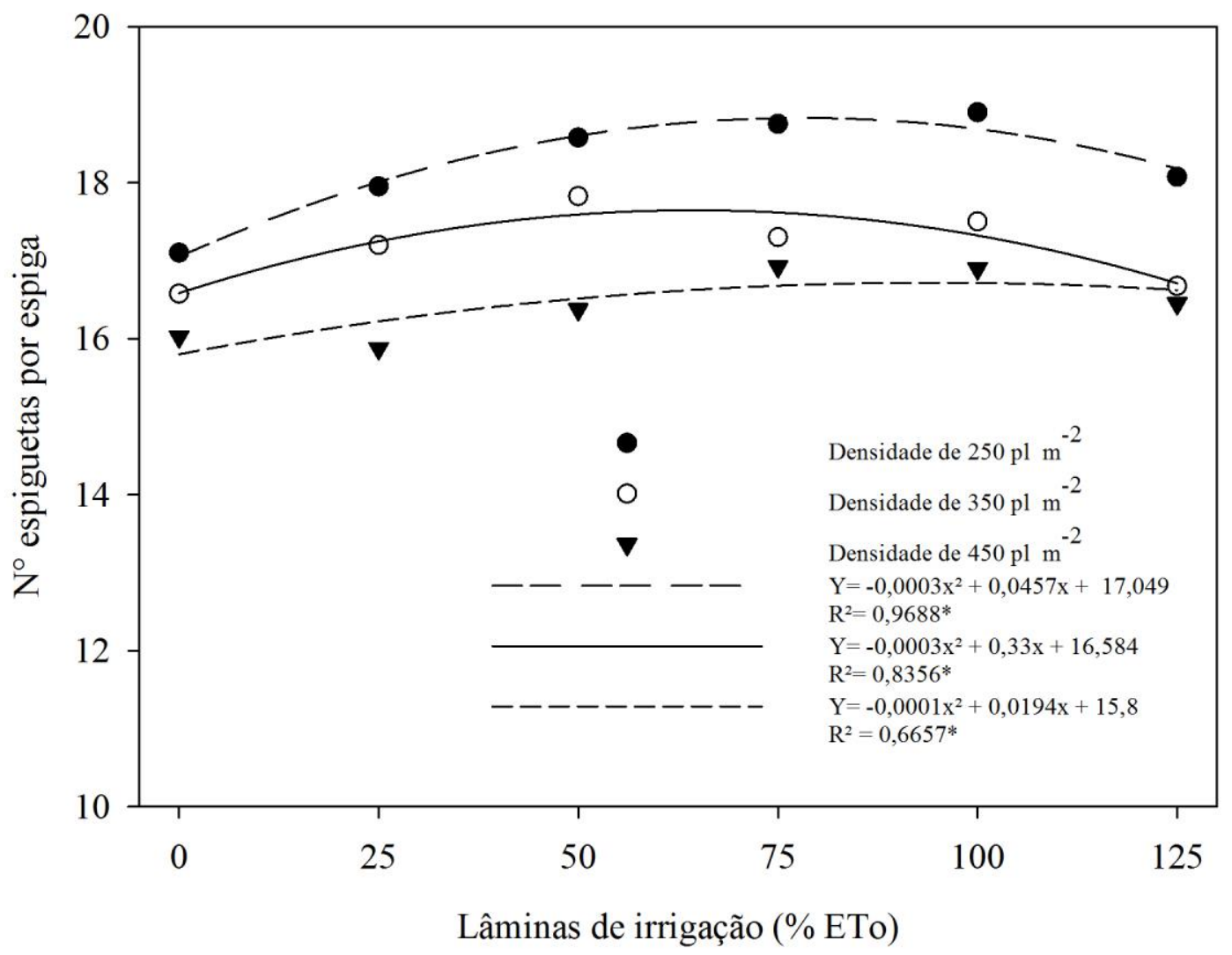

*significativo a 0,05 de probabilidade pelo teste $\mathrm{F}$. *significant at 0.05 probability by $F$ test.

Figura 3. Variação no número de espiguetas por espiga de trigo em função de diferentes densidades de semeadura e lâminas de irrigação suplementar. Variation in the number of spikelets per ear of wheat as a function of different sowing densities and supplemental irrigation slides.

Os pontos de máxima eficiência técnica para este componente são obtidos nas lâminas de $76,2 \%$ da ETo $(18,8), 55,0 \%$ da ETo $(17,2)$ e $97,0 \%(16,7)$ para as densidades de 250,350 e $450 \mathrm{pl} \mathrm{m}^{-2}$, respectivamente.

Os resultados observados corroboram com os verificados por Gross et al. (2012), que testando métodos de semeadura e densidades 60,320 e 480 plantas por $\mathrm{m}^{-2}$, observaram acréscimo linear do número de espiguetas por $\mathrm{m}^{-2}$ à medida que se aumentou a densidade de semeadura.

Analisando-se as médias do número de grãos por espiga, representados na Figura 4, foi possível constatar maiores valores nas lâminas de irrigação de 75 e 100\% da ETo. Os menores valores do número de grãos por espiga ocorreram para a testemunha sem irrigação $(0 \%$ da ETo). Observa-se também que o incremento no número de grãos por espiga foi proporcionado pelo aumento dos níveis de irrigação. 


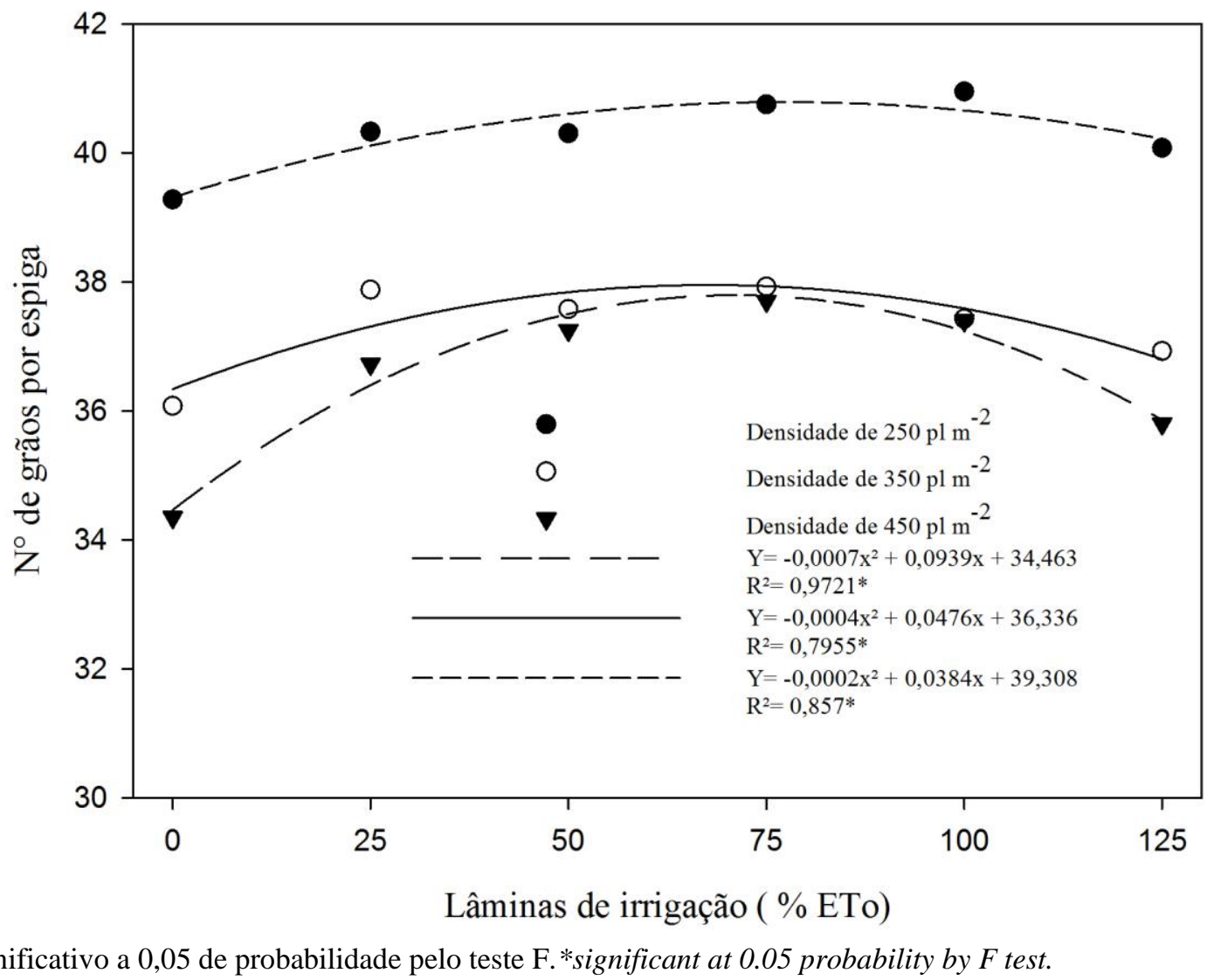

*significativo a 0,05 de probabilidade pelo teste $\mathrm{F}$. *significant at 0.05 probability by $F$ test.

Figura 4. Número de grãos por espiga em função de diferentes densidades de semeadura e lâminas de irrigação. Number of grains per spike in function of different seeding densities and irrigation blades.

Os pontos de máxima eficiência técnica para o componente número de grãos por espiga foram obtidos nas lâminas de 67,1\% da ETo $(37,6), 59,5 \%$ da ETo $(37,8)$ e 96,0\% $(41,2)$ para as densidades de 250,350 e $450 \mathrm{pl} \mathrm{m}^{-2}$, respectivamente.

Os resultados obtidos para o componente número de grãos por espiga diferem dos observados por Zagonel et al. (2002) e Valério et al. (2008), que testando diferentes densidades de plantas, em trigo, constataram que ocorre redução linear negativa no número de grãos por espiga em função do aumento de densidade, fato que pode ser explicado pela grande competição entre plantas e pelos recursos do ambiente durante seu desenvolvimento.

Para o número de espigas por metro quadrado houve variação estatística significativa em função das diferentes lâminas de irrigação e densidades de semeadura (Figura 5). 


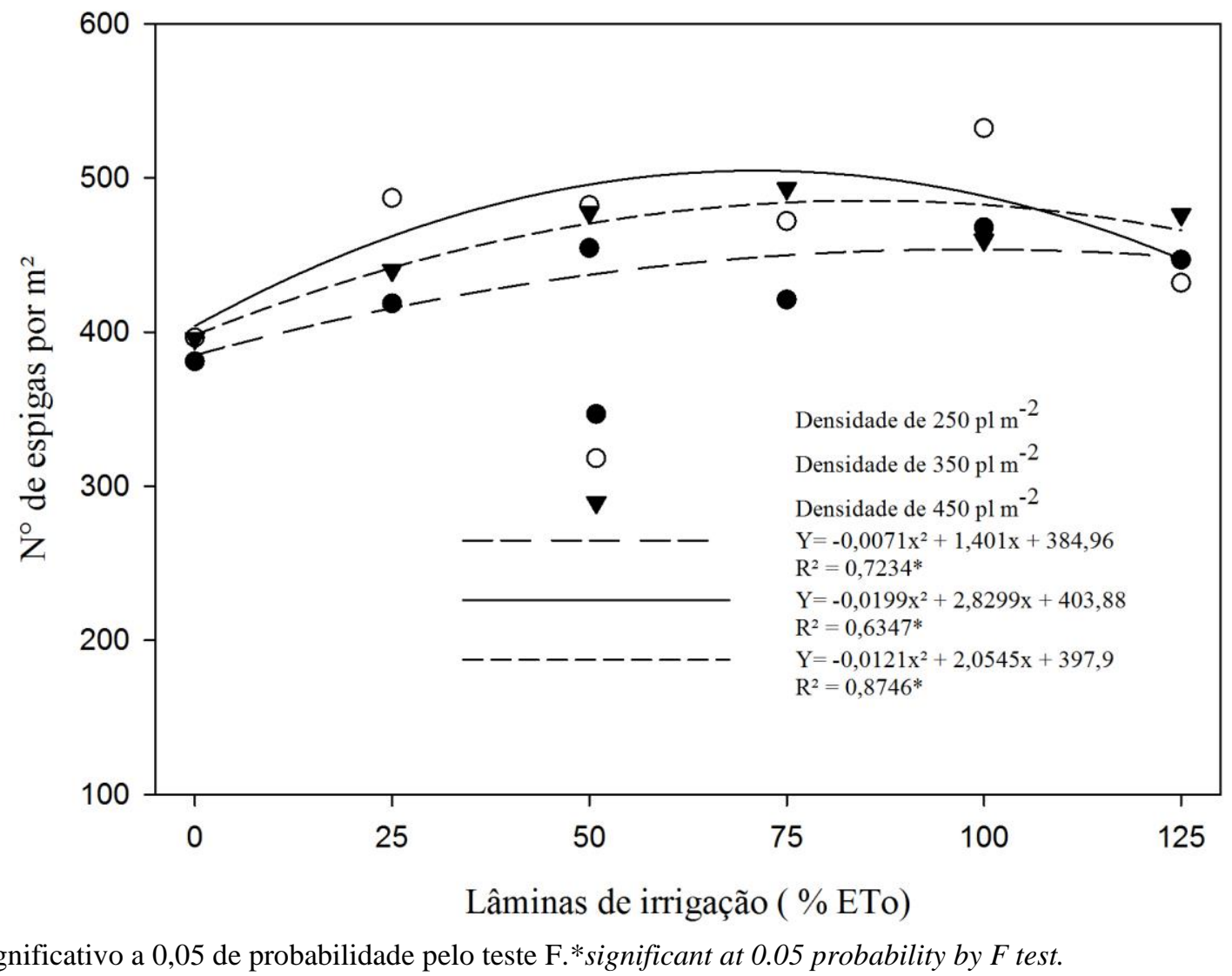

Figura 5. Número de espigas por metro quadrado em função de diferentes densidades de semeadura e lâminas de irrigação. Number of spikes per square meter as a function of different seeding densities and irrigation depths.

Nas densidades de 250, 350 e $450 \mathrm{pl} \mathrm{m}^{-2}$, conforme houve aumento da lâmina de irrigação, o mesmo ocorreu para o número de espigas por $\mathrm{m}^{-2}$ até a lâmina de $100 \%$ da ETo, onde os maiores valores foram observados na densidade de $350 \mathrm{pl} \mathrm{m}^{-2}$. Esse foi o componente que melhor explicou o aumento na produtividade em relação ao fator densidade de plantas. Estes resultados contrariam os obtidos por Almeida et al. (2004) que relatam, que apesar da quantidade de espigas em cereais de inverno aumentar de acordo coma a densidade de semeadura, não ocorre diferença significativa em função da capacidade de perfilhamento da cultura, desde que ocorra variação entre 180 e 570 pl m².

O incremento no número de espigas por metro quadrado nas menores populações de plantas pode ser considerado, de acordo com Valério et al. (2008), como um claro indicativo do potencial da cultura em compensar a falta de espaço através da emissão e manutenção de perfilhos.

Os pontos de máxima eficiência técnica para a varável número de espigas por metro quadrado são obtidos nas lâminas de $98,7 \%$ da ETo $(454,1), 71,1 \%$ da ETo $(504,5)$ e 84,9\% $(485,1)$ para as densidades de 250,350 e $450 \mathrm{pl} \mathrm{m}^{-2}$, respectivamente.

Para a massa de mil grãos notou-se interação significativa entre os fatores analisados (Figura 6). 


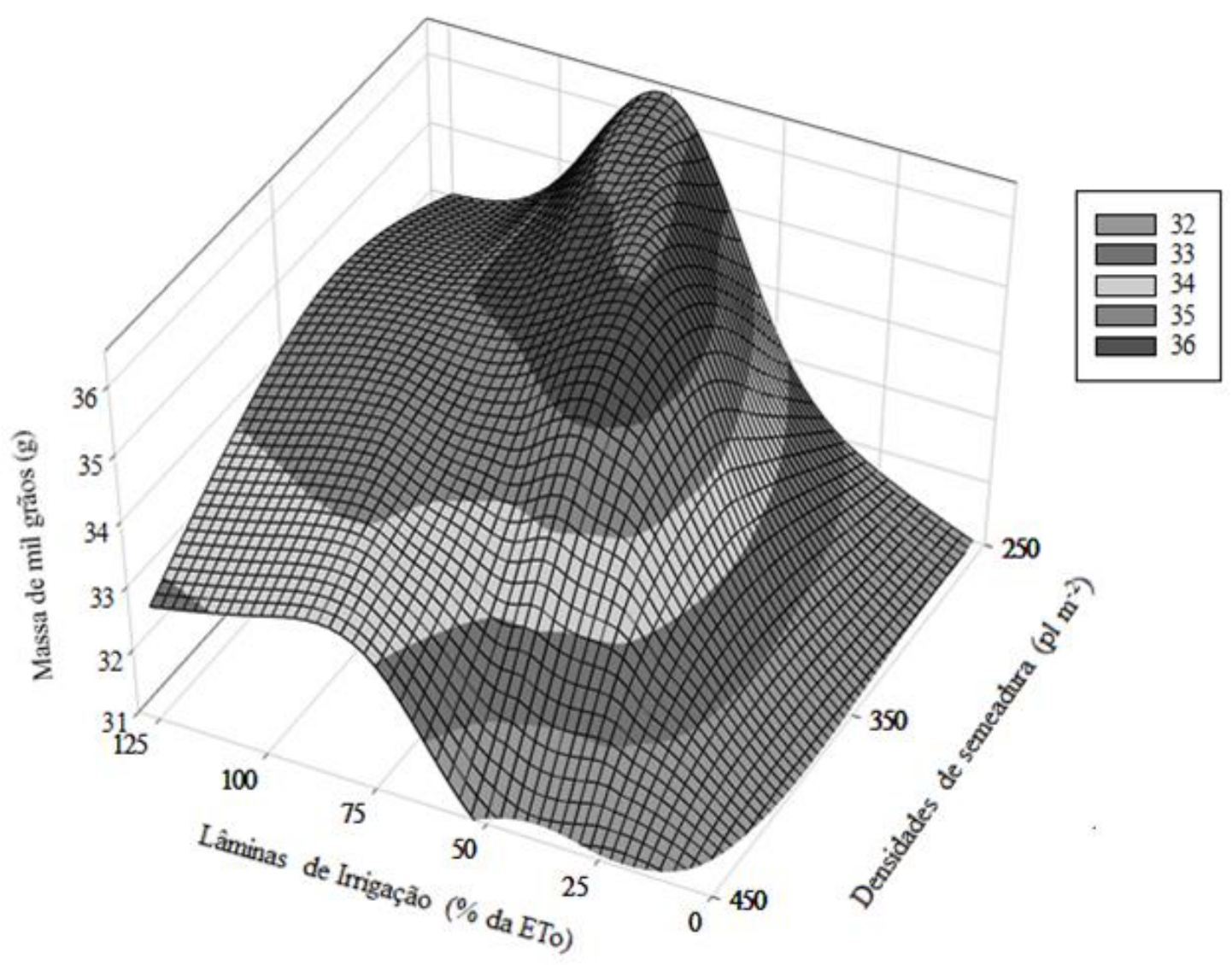

Figura 6. Influência de diferentes densidades de semeadura e lâminas de irrigação sobre a massa de mil grãos de trigo. Influence of different sowing densities and irrigation slides on the mass of a thousand wheat grains.

Os maiores valores de massa de mil grãos foram observados na densidade de $350 \mathrm{pl} \mathrm{m}^{-2}$, onde o maior valor médio obtido foi na lâmina de 50\% ETo $(35,6 \mathrm{~g})$. Esses resultados diferem dos obtidos por Pauli e Primieri (2016), que não observaram diferenças significativas sobre a massa de mil grãos de trigo cultivado nas densidades de 300,350 e $400 \mathrm{pl} \mathrm{m}^{-2}$.

Tavares et al. (2014), avaliando genótipos de trigo cultivados em densidades variando entre 150 e $450 \mathrm{pl} \mathrm{m}^{-2}$, em duas localidades do estado do Paraná, observaram ajuste quadrático para massa de mil grãos, em função das densidades de semeadura, obtendo maior média na densidade de $341 \mathrm{pl} \mathrm{m}^{-2}$, corroborando com os resultados evidenciados no presente estudo.

Em relação ao peso médio do hectolitro, a partir do ajuste obtido, observa-se que houve interação significativa entre os fatores lâminas de irrigação e densidades de semeadura testadas. Conforme representado na Figura 7, os maiores valores $\left(78,9\right.$ e 78,6 $\left.\mathrm{kg} \mathrm{hL}^{-1}\right)$ foram observados nas lâminas de $100 \%$ e $75 \%$ da ETo nas densidades de 350 e 450 pl m², respectivamente. 


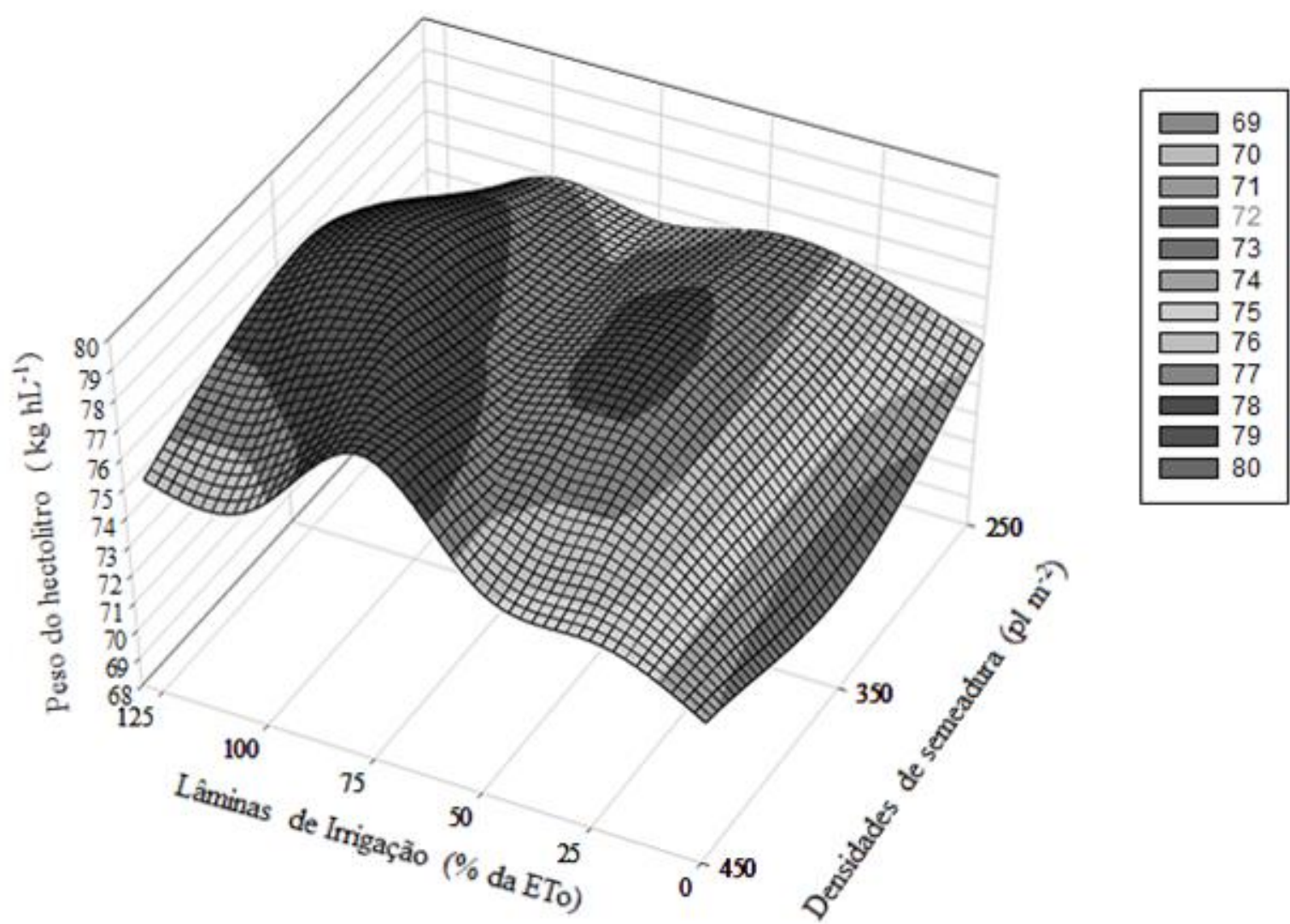

Figura 7. Influência de diferentes densidades de semeadura e lâminas de irrigação sobre o peso do hectolitro $(\mathrm{pH})$ do trigo. Influence of different seeding densities and irrigation depths on the weight of the hectoliter $(\mathrm{pH})$ of the wheat.

$\mathrm{Na}$ densidade de $250 \mathrm{pl} \mathrm{m}^{-2}$ os valores de peso do hectolitro oscilaram entre $73-81$ (lâmina de $125 \%$ da ETo) e $76,13 \mathrm{~kg} \mathrm{hL}^{-1}$ (lâmina de $50 \%$ da ETo). Para densidade de $350 \mathrm{pl}$ $\mathrm{m}^{-2}$ foram de 71,62 (tratamento sem irrigação) e 78,89 $\mathrm{kg} \mathrm{hL}^{-1}$ (100\% da ETo), e na densidade de $450 \mathrm{pl} \mathrm{m}^{-2}$ o mínimo foi de 73,10 (tratamento sem irrigação) e máximo de 78,63 kg hL (lâmina de $75 \%$ da ETo).

Este comportamento pode ser explicado pelo fato de o fornecimento de água favorecer o enchimento de grãos, aumentando assim, sua massa. Frizzone et al. (1996), estudando o efeito de lâminas de irrigação com doses de nitrogênio, observaram que tanto o excesso quanto o déficit de irrigação fizeram diminuir o peso do hectolitro.

A massa do hectolitro é um índice referente ao rendimento dos grãos em farinha, por isso, espera-se que amostras com elevada massa do hectolitro apresentem maiores rendimentos. Os valores da massa do hectolitro desejados situam-se acima de $78 \mathrm{~kg} \mathrm{hL}^{-1}$, valor mínimo exigido para a classificação do trigo como tipo 1 (BRASIL, 2001). Grãos com valores inferiores ao dessa massa sofrem desvalorização no mercado no momento da comercialização. No presente estudo, embora os valores médios de peso do hectolitro tenham sido próximos ao valor exigido, apenas os tratamentos de $100 \%$ da ETo na densidade de 350 $\mathrm{pl} \mathrm{m}{ }^{-2}$ e $75 \%$ da ETo na densidade de $450 \mathrm{pl} \mathrm{m}^{-2}$, apresentaram médias superiores a $78 \mathrm{~kg} \mathrm{hL}$ 1 . 
Neste trabalho observou-se produtividade mínima de $4165 \mathrm{~kg} \mathrm{ha}^{-1}$ e máxima de $6894 \mathrm{~kg}$ ha $^{-1}$, nos tratamentos sem irrigação $\left(0 \%\right.$ da ETo na densidade de $\left.450 \mathrm{pl} \mathrm{m}^{-2}\right)$ e na lâmina de irrigação de $100 \%$ da ETo (densidade de $350 \mathrm{pl} \mathrm{m}^{-2}$ ), respectivamente. Para este parâmetro, a análise de variância indicou que houve efeito significativo em função das diferentes lâminas de irrigação. Pode-se observar na Figura 8 que para todas as densidades de semeadura testadas, ocorreu aumento de produtividade em todas as lâminas de irrigação em comparação à testemunha não irrigada (0\% da ETo).

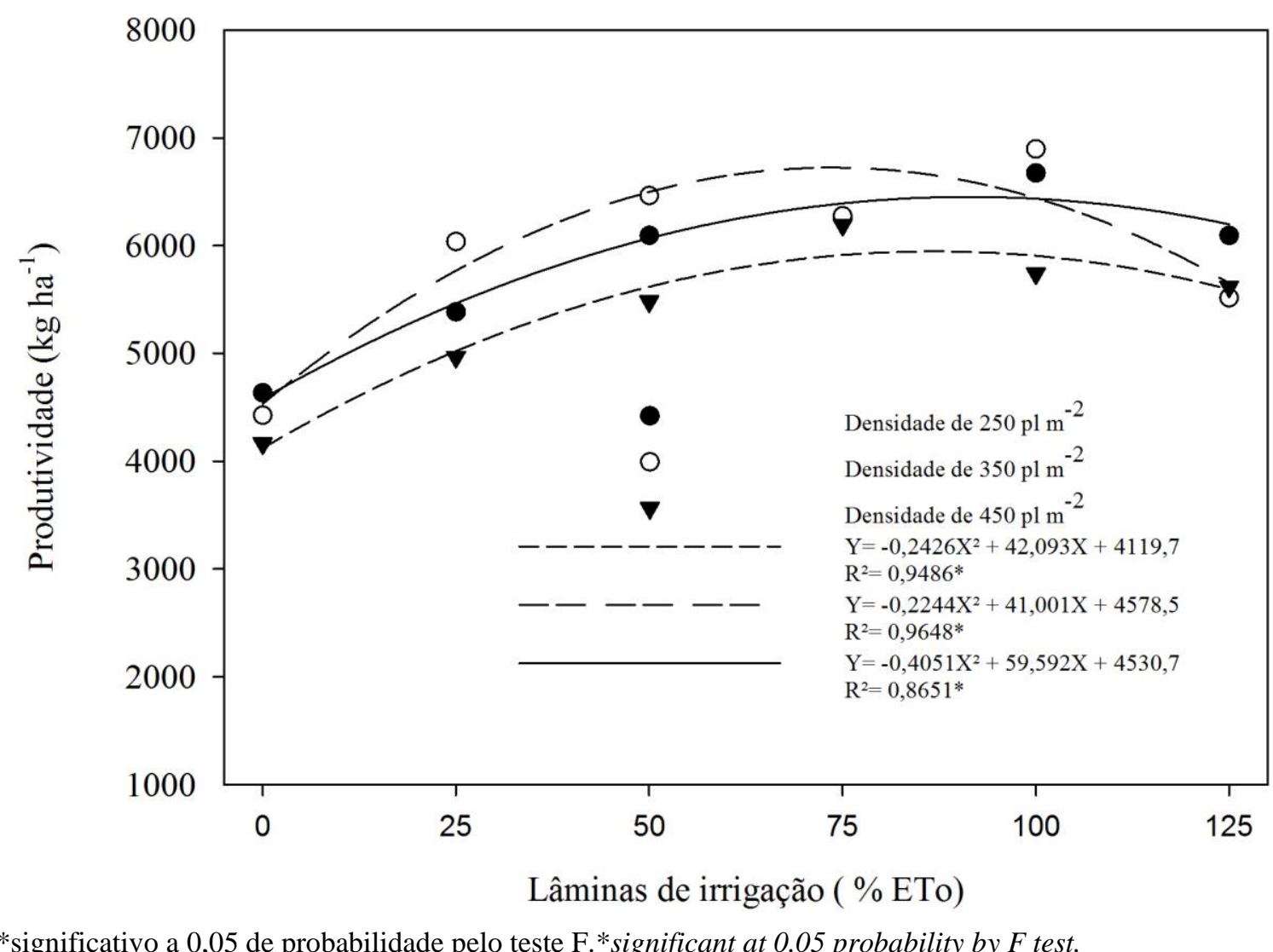

Figura 8. Produtividade de trigo em $\mathrm{kg} \mathrm{ha}^{-1}$ em função de três níveis de densidade de semeadura e seis lâminas de irrigação. Wheat yield in $\mathrm{kg} \mathrm{ha}^{-1}$ according to three levels of seeding density and six irrigation slides.

A produtividade mínima na densidade de $250 \mathrm{pl} \mathrm{m}^{-2}$ foi de $4632 \mathrm{~kg} \mathrm{ha}^{-1}$ na testemunha (sem irrigação) e máxima de $6671 \mathrm{~kg} \mathrm{ha}^{-1}$ (tratamento de 100\% da ETo). Na densidade de 350 pl m${ }^{-2}$, os valores oscilaram entre $4425 \mathrm{~kg} \mathrm{ha}^{-1}$ (testemunha sem irrigação) e $6894 \mathrm{~kg} \mathrm{ha}^{-1}$ (tratamento de $100 \%$ da ETo). Para a densidade de $450 \mathrm{pl} \mathrm{m}^{-2}$ a mínima observada foi de 4165 $\mathrm{kg} \mathrm{ha}^{-1}$ na testemunha (sem irrigação) e máxima de $6192 \mathrm{~kg} \mathrm{ha}^{-1}$ (tratamento de $75 \%$ da ETo).

O decréscimo de produtividade em função da diminuição de lâmina aplicada também foi observado por Daniel (2011), que estudando o efeito de lâminas de irrigação em trigo em diferentes cultivares, observou que de acordo com a diminuição das lâminas de irrigação houve redução significativa na massa de mil grãos, peso do hectolitro e produtividade, para todas as cultivares estudadas. 
Os pontos de máxima eficiência técnica para produtividade são obtidos nas lâminas de 91,36\% da ETo (6451 $\left.\mathrm{kg} \mathrm{ha}^{-1}\right), 73,55 \%$ da ETo (6380 $\left.\mathrm{kg} \mathrm{ha}^{-1}\right)$ e 86,75\% da ETo (6447 $\mathrm{kg} \mathrm{ha}^{-}$ $\left.{ }^{1}\right)$ para as densidades de 250,350 e $450 \mathrm{pl} \mathrm{m}^{-2}$, respectivamente.

Estes resultados corroboram com os observados por Fioreze (2011), que comenta que mesmo com menor número de espigas por metro quadrado, maiores valores de produtividade foram observados para menores densidades de semeadura em função do incremento do rendimento individual por espiga, através do aumento do tamanho, número e massa de grãos.

\section{CONCLUSÕES}

As lâminas de irrigação e densidades de semeadura influenciaram significativamente o número de espiguetas por espiga, número de espigas por metro quadrado e massa de mil grãos.

A maior produtividade de grãos de trigo foi encontrada pela combinação de $350 \mathrm{pl} \mathrm{m}^{-2}$ com a lâmina de irrigação de $100 \%$ da ETo.

A interação entre os fatores lâmina de irrigação e densidade de semeadura exerceu influência significativa sobre a massa de mil grãos e peso do hectolitro.

A escolha da densidade de plantas é uma variável decisiva no cultivo de trigo irrigado, influenciando significativamente nos componentes de produção.

\section{REFERÊNCIAS BIBLIOGRÁFICAS}

ACEVEDO, E.; SILVA, P.; SILVA, H. Wheat growth and physiology. In: CURTIS, B. C.; RAJARA, S.; MACPHERSON, H. G. (ed.). Bred Wheat: improvement and production. Rome: FAO. 2002. p. 39-70.

ALLEN, R. G.; PEREIRA, L. S.; RAES, D.; SMITH, M. Crop evapotranspiration: Guidelines for computing crop water requirements. Rome: FAO, 1998. 300 p. (FAO Irrigation and Drainage Paper, 56).

ALMEIDA, L. A.; MUNDSTOCK, C. M. A qualidade da luz afeta o afilhamento em plantas de trigo, quando cultivadas sob competição. Ciência Rural, Santa Maria, v. 31, n. 3, p.401408, 2001.

ALMEIDA, M. L.; SANGOI, L.; MEROTTO JR., A.; ALVES, A. C.; NAVA, I. C.; KNOPP, A. C. Tiller emission and dry mass accumulation of wheat cultivars under stress. Scientia Agricola, Piracicaba, v. 61, n. 3, p.266-270, 2004.

AVARENGA, C. B.; SOBRINHO, J. S.; SANTOS, E. M. Comportamento de cultivares de trigo em diferentes densidades de semeadura sob irrigação indicadas para a região do Brasil central. Bioscience Journal, Uberlândia, v. 25, n. 5, p.98-107, 2009.

AZEVEDO, J. A.; OLITTA, A. F. L.; SILVA, E. M.; GUERRA, A. F. Comprimento de raízes e extração de água do trigo irrigado, em função de níveis diferenciados de tensão de água no solo em três etapas de desenvolvimento. In: Relatório técnico anual do centro de 
pesquisa agropecuária dos cerrados 1987/1990. Anais. Planaltina: Embrapa-CPAC, 1994. p. 174-179.

BRASIL. Ministério da Agricultura, Pecuária e Abastecimento. Instrução Normativa $\mathrm{n}^{\circ}$ 7, de 15 de agosto de 2001. Lex: Diário Oficial da União, Brasília, seção 1, p.33, 2001.

BRUNETTA, D.; DOTTO, S. R.; TAVARES, L. C. V. Pluviosidade e rendimento de trigo no Norte do Paraná. Boletim de Pesquisa/Embrapa Soja, Londrina, n. 4, p. 20, 2001.

COMPANHIA NACIONAL DE ABASTECIMENTO - CONAB. Levantamentos de Safra. Brasília, DF, 2018. Disponível em: http://www.conab.gov.br/conabweb/. Acesso em: 04 de jun. 2018.

DANIEL, T. A. D. Avaliação de níveis de irrigação sobre as componentes de produção e produtividade de cultivares de trigo (Triticum aestivum L.) no município de Tangará da Serra-MT. 2011. 154 f. Dissertação (Mestrado em Agricultura Tropical) - Faculdade de Agronomia e Medicina Veterinária, Universidade Federal do Mato Grosso, Cuiabá, 2011.

EMPRESA BRASILEIRA DE PESQUISA AGROPECUÁRIA - EMBRAPA. Manual de métodos de análise de solo. Rio de Janeiro: Centro Nacional de Pesquisa de Solos. 2011. 230 p.

EMPRESA BRASILEIRA DE PESQUISA AGROPECUÁRIA - EMBRAPA. BRS Marcante. Passo Fundo, 2018. Disponível em: https://ainfo.cnptia.embrapa.br/digital/bitstream/item/121597/1/FD-0383.pdf. Acesso em 26 jun. 2018.

FIOREZE, L. S. Comportamento produtivo do trigo em função da densidade de semeadura e da aplicação de reguladores vegetais. 2011. 73 f. Dissertação (Mestrado em Agronomia/Agricultura) - Faculdade de Ciências Agronômicas, Universidade Estadual Paulista, Botucatu, 2011.

FRIZZONE, J.; MÉLlO JÚNIOR, A. V.; FOLEGATTI, M. V.; BOTREL, T. A. Efeito de diferentes níveis de irrigação e adubação nitrogenada sobre componentes de produtividade da cultura de trigo. Pesquisa Agropecuária Brasileira, Brasília, v.31, n. 6, p.425-434, 1996.

GROSS, T. F.; DIAS, A. F.; KAPPES, C.; SCHIEBELBEIN, M. ANSELMO, J. L.; HOLANDA, H. V. Comportamento produtivo do trigo em diferentes métodos e densidades de semeadura. Scientia Agraria Paranaensis, Marechal Cândido Rondon, v. 11, n. 4, p.50-60, 2012.

LARGE, E. C. Growth stages in cereais. Illustration of the Feekes Scale. Plant Pathology, London, v. 3, p.128-129, 1954.

LIBARDI, V. C M.; COSTA, M. B. Consumo de água da cultura do trigo (Triticum aestivum L.). Revista da Faculdade de Zootecnia, Veterinária e Agronomia, Uruguaiana, v. 4, n. 1, p.16-23, 1997.

MILLAR, A. A. Drenagem de terras agrícolas: bases agronômicas. São Paulo: McGrawHill do Brasil LTDA., 1978. 276 p. 
OZTURK, A.; CAGLAR, O.; BULUT, S. Growth and yield response of facultative wheat to winter sowing, freezing sowing and sping sowing at different seeding rates. Journal of Agronomy and Crop Science, Berlim, v. 192, n. 1, p.10-16, 2006.

PAULI, J. P.; PRIMIERI, C. Resposta da cultura do trigo em função do efeito espaçamento entre linhas e densidade de semeadura. Revista Cultivando o Saber, Cascavel, v. 9, n. 1, p.56-61, 2016.

PROVENZI, F. D.; BERGAMO, R.; DEBASTIANI, W.; BALBINOT JUNIOR, A. A. Arranjo espacial de plantas em duas cultivares de trigo. Unoesc \& Ciência - ACET, Joaçaba, v. 3, n. 1, p.31-36, 2012.

SCALCO, M. S.; FARIA, M. A.; GERMANI, R.; MORAIS, A. R. Produtividade e qualidade industrial do trigo sob diferentes níveis de irrigação e adubação. Revista Ciência Agrotecnológica, Lavras, v. 26, n. 2, p.400-410, 2002.

SILVA, J. A. G.; ARENHARDT, E. G.; KRUGER, C. A. M. B.; LUCCHESE, O. A.; METZ, M.; MAROLLI, A. A expressão dos componentes de produtividade do trigo pela classe tecnológica e aproveitamento do nitrogênio. Revista Brasileira de Engenharia Agrícola e Ambiental, Campina Grande, v. 19, n. 1, p.27-33, 2015.

SLEEPER, D. A.; POEHLMAN, J. M. Breeding field crops. Ames: Blackwell Pub Iowa, 2006. $424 \mathrm{p}$.

STRECK, E. V.; KAMPF, N.; DALMOLIN, R. S. D.; KLAMT, E.; NASCIMENTO, P. C.; SCHNEIDER, E.; PINTO, L. F. S. Solos do Rio Grande do Sul. Porto Alegre: Emater, 2008. $222 \mathrm{p}$.

TAVARES, L. C. V.; FOLONI, J. S. S.; BASSOI, M. C.; PRETE, C. E. C. Genótipos de trigo em diferentes densidades de semeadura. Pesquisa Agropecuária Tropical, Goiânia, v. 44, n. 2, p.166-174, 2014.

VALÉRIO, I. P.; CARVALHO, F. I. F.; OLIVEIRA, A. C.; MACHADO A. A.; BENIN, G.; SCHEEREN, P. L.; SOUZA, V. Q.; HARTWIG, I. Desenvolvimento de afilhos e componentes do rendimento em genótipos de trigo sob diferentes densidades de semeadura. Pesquisa Agropecuária Brasileira, Brasília, v. 43, n. 3, p.319-326, 2008.

ZAGONEL, J.; VENANCIO, W. S.; KUNZ, R. P.; TANAMATI, H. Doses de nitrogênio e densidades de plantas com e sem um regulador de crescimento afetando o trigo, cultivar OR1. Ciência Rural, Santa Maria, v. 32, n. 1, p.25-29, 2002. 